\title{
Imigrantes nos media portugueses: representações das minorias no início do milênio
}

Isabel Maria Ribeiro Ferin da Cunha ${ }^{1}$

Professora do Instituto de Estudos Jornalísticos da Universidade de Coimbra.

Coordenadora do projeto Mídia, Imigração e Minorias Étnicas.

E-mail: barone.ferin@netcabo.pt

A partir do fim de 1998, assiste-se, em Portugal, ao esgotamento de um modelo econômico promovido com o intuito de aplicar Fundos de Apoio Comunitário em projetos de obras públicas e privadas, angariadores de mão-de-obra numerosa. Simultaneamente, no plano internacional, entram em dificuldades as empresas da designada nova economia, fundadas em tecnologias de informação e comunicação, fato que vai penalizar grandemente os grupos com interesses nos media. No mesmo período dá-se a expansão da televisão a cabo, contribuindo para que as de sinal aberto percam uma porcentagem vultosa de suas audiências. Essas dificuldades aprofundam as estratégias de concorrência e promovem a racionalização de recursos, gerando maior precariedade no trabalho dos jornalistas.

É preciso ainda mencionar que esses anos correspondem à entrada de milhares de jovens formados por cursos superiores no mercado de trabalho da informação e da comunicação, o que, ao estimular a saudável competição, favorece a rotatividade e a não-responsabilização trabalhista das empresas.

Entre 1999 e 2002, a imigração de grupos dos PALOP (Países Africanos de Língua Oficial Portuguesa) e de outros países africanos perde peso, adquirindo enorme visibilidade as correntes migratórias originárias do Brasil e dos países do Leste Europeu, sobretudo de ucranianos. Em 2002, o SEF (Serviço de Estrangeiros e Fronteiras) contabiliza cerca de 300 mil imigrantes com residência legal, sendo que, pela primeira vez, os imigrantes de origem cabo-verdiana tendem a ser ultrapassados pelos de origem brasileira e ucraniana.

Nesse período, podem-se identificar, na imprensa e na televisão, quatro tematizações com agendas rotineiras. A primeira centra-se nas gangs de jovens

1. Com a colaboração de Clara Almeida Santos, professora do Instituto de Estudos Jornalísticos da Universidade de Coimbra. 
comunicação \& educação • Ano XII • Número 2 • maio/ago 2007

2. FERIN, I. Immigrations Africaine et Est-Européenne au Portugal: Deux Traitements Médiatiques (Imigração africana e do Leste Europeu: duas abordagens midiáticas). Rev. Lusotopie, Paris, nov. 91, p. 102, 2001; Id. Imagens da imigração em Portugal. Revista Media e Jornalismo, 2: 71- 87, 2003.

3 A TVI - Televisão Independente é a segunda estação de televisão portuguesa de caráter privado, com transmissão iniciada em 1993. Primeiramente controlada por empresas da Igreja Católica, hoje é administrada pelo grupo de comunicação social Media Capital. Em 2000 apostou em programas de ficção nacional, novelas, programas infantis, novos noticiários, e em reality shows, como o Big Brother. (N.E.)

4. A SIC - Sociedade Independente de Comunicação foi o primeiro canal de televisão privado, independente e comercial a operar em Portugal, encerrando 35 anos de monopólio estatal no mercado televisivo português. (N.E.)

5. VIAGEM à Ucrânia. Cristina Boavida, SIC, 4 dez. 2002.

6. Prime-time: horário nobre. É o bloco da programação televisiva no meio da noite. Em Portugal, o horário nobre é compreendido entre 20 e 23 horas (hora de Portugal Continental). (N.E.) da designada segunda geração de imigrantes dos PALOP, que surge nas primeiras páginas dos jornais de referência e faz chamadas nos jornais televisivos, principalmente em julho de 2000. A segunda tematização foca a imigração do Leste, tratando-a em duas perspectivas concomitantes: histórias de vida e poder das máfias. A terceira apresenta as alterações à lei de imigração, em 2000, e o novo período extraordinário de legalização. A quarta e última tematização visa à imigração na Europa associando-a, de forma crescente, à crise demográfica e às alterações do Código do Trabalho em Portugal, atingindo grande relevância na Reunião da Cúpula Européia de Sevilha, presidida pela Espanha (dirigida pelo primeiro-ministro José Maria Aznar e com a presença do recém-eleito primeiro-ministro português Durão Barroso), em junho de 2002.

Em um balanço desses anos, pode-se dizer que há progressivo interesse e a especialização dos jornalistas da imprensa de referência no tema imigração $e$ minorias. Tal interesse e a especialização refletem-se nos enquadramentos das matérias, na informação estatística veiculada e na linguagem utilizada. No entanto, há ainda muitos artigos que usam histórias descontextualizadas e fotografias de arquivo (por exemplo, toda a cobertura realizada em julho de 2000 do Caso dos Assaltos às Bombas da CREL - Circular Regional Exterior de Lisboa), o que sinaliza práticas menos conscienciosas com possíveis efeitos na percepção pública da comunidade representada ${ }^{2}$. Nas televisões, a crescente luta pelas audiências - de que o programa Big Brother, iniciado na TVI ${ }^{3}$ em setembro de 2000, é exemplo - faz oscilar muitos dos princípios éticos do jornalismo, abrindo espaços para o infotainment e a prevalência das notícias leves, elementos que contaminam o tratamento das temáticas imigração e minorias. $\mathrm{O}$ caso mais flagrante é a exibição espetacularmente anunciada, no noticiário da $\mathrm{SIC}^{4}$, de uma reportagem muito contundente, inicialmente proposta para um outro horário, sobre a casa de correção de Vila Fernando, em Elvas (local onde se encontravam detidos jovens assaltantes da CREL), no dia em que acontecia, no outro canal, a saída do então famoso Marco da casa do Big Brother.

Estas observações não impedem de ressaltar alguns bons trabalhos na televisão, como aquele que recebeu o prêmio ACIME (Alto Comissariado para a Imigração e as Minorias Étnicas), de 2002, intitulado Viagem à Ucrânia ${ }^{5}$. Porém, o seu impacto é limitado, pois normalmente são exibidos fora do prime-time ${ }^{6}$.

\section{UMA REALIDADE EM CONSTANTE MUTAÇÃO}

A partir de 2002, coincidindo com uma nova política européia para a imigração, o governo português implementa, através do Alto Comissariado para a Imigração e as Minorias Étnicas, medidas públicas e privadas de apoio à regularização e integração dos imigrantes. Tais medidas traduzem-se em alteração de legislação, ações de apoio e programas de sensibilização junto de agentes institucionais e privados, bem como da população em geral. Dentre 
Imigrantes nos media portugueses - Isabel Maria Ribeiro Ferin da Cunha

essas ações, destacam-se os apoios concedidos a estudos científicos sobre as imigrações, nomeadamente na perspectiva dos media ${ }^{7}$.

Refletindo mudanças européias, inicia-se em Portugal um período de reajustamento de políticas e fluxos, estimando-se por volta de $500 \mathrm{mil}$ os imigrantes residentes legalmente em Portugal, o que constitui cerca de $10 \%$ da população ativa e $5 \%$ da população em território português. Por outro lado, as dificuldades econômicas de Portugal, as novas políticas para o trabalho e o fim do ciclo de grandes construções criaram fenômenos de desemprego e aumentaram a precariedade dos trabalhadores imigrantes e daqueles sem documentos, sendo freqüentes os alertas emitidos pelas associações de imigrantes, organizações católicas e centrais sindicais. Assim, ao mesmo tempo que se assiste a uma crescente mobilização ante questões sociais, surgem novas formas de discriminação e exclusão, com base nas origens étnicas e aptidões quanto ao trabalho e à produtividade .

$\mathrm{Na}$ perspectiva dos media, esse período caracteriza-se por grandes dificuldades dos grupos neles interessados, na medida em que estão cada vez mais diversificados e, num clima de crise prolongada, todo o grupo tende a ser afetado. As televisões generalistas continuam sendo as mais prejudicadas, recorrendo os seus diretores a reestruturações freqüentes e a engenharias de otimização dos produtos/programas nas grades. Os jornais televisivos vão refletir essa contenção ao insistirem em notícias leves (às quais o cidadão comum é normalmente exposto) e no infotainment, matérias que exigem menos dinheiro na sua produção e audiência mínima garantida.

Ao descrever esses anos convém, mais uma vez, mencionar que a imprensa de referência adquiriu, de maneira geral, grande especialização e conhecimento das temáticas imigração e minorias, para além de ter aprofundado, no seu tratamento, a concepção de jornalismo de interesse do público ou de jornalismo cívico $^{9}$. Os trabalhos mais importantes encontram-se nos jornais Público e Diário de Notícias, e na revista Visão, nomeadamente focando as seguintes matérias: a imigração brasileira em Portugal, a exclusão e a pobreza dos imigrantes sem trabalho, procedimentos do novo período da legalização dos imigrantes em situação ilegal, bem como temáticas que visam apresentar percursos de integração na comunidade de acolhimento. No entanto, é preciso lembrar que a cobertura jornalística na imprensa continua a incidir, numa perspectiva quantitativa, principalmente sobre as temáticas crime (homicídios, máfias, prostituição) e violência (demolição e confrontos em bairros de comunidades ciganas) ${ }^{10}$.

Nesse mesmo período as televisões generalistas não suscitam, geralmente, uma análise positiva. $\mathrm{Na}$ verdade, o trabalho exaustivo de análise do prime-time dos jornais televisivos, realizado com o apoio do ACIME, durante o ano de 2003 e até outubro de 2004, mostra algumas constantes, quanto aos formatos, conteúdos e imagens veiculadas, que, não sendo exclusivas das notícias sobre imigração e minorias étnicas, tendem a introduzir uma percepção negativa sobre essas comunidades. É preciso frisar a importância do prime-time nas televisões
7. ACOLHER e integrar: três anos ao serviço dos imigrantes. Relatório de Actividades do Alto Comissariado para a Imigração e Minorias Étnicas (2002/2005), Lisboa: ACIME.

8. SANTOS, N. Tensões raciais inevitáveis: as empresas portuguesas despedem os trabalhadores de origem africana e substituem-nos por imigrantes de Leste, uma mão-de-obra com mais formação. Expresso, Caderno Economia, p. 3, 22 maio 2004.

9. TRAQUINA, N.; MESQUITA, M. Jornalismo cívico. Lisboa: Livros Horizonte, 2003.

10. FERIN, I. et al. Media, imigração e minorias. Lisboa: OI/ACIME, 2004. 
generalistas, pois é aí, por cerca de três horas, que a visualização das emissões é mais concorrida e a informação veiculada causará maior impacto ${ }^{11}$.

Primeiramente, é necessário citar que no horário do prime-time os gêneros jornalísticos são pouco variados, isto é, o gênero dominante é a reportagem (um âncora, mais intervenção de um repórter e imagens exteriores), havendo poucas entrevistas e debates em estúdio, que são mais freqüentes nos jornais da manhã, da tarde ou da meia-noite. Por outro lado, nota-se a utilização de imagens de arquivo, por vezes sem que elas sejam identificadas como tal (por exemplo, nas notícias sobre bairros de maioria étnica oriunda dos países africanos de língua portuguesa ou de etnia cigana, bem como naquelas sobre confusões em bares de prostituição).

Em segundo lugar, nota-se que os três canais analisados emitem, na maior parte das vezes, as mesmas informações, o que deverá ser lido em conjunto com a natureza das fontes predominantemente institucionais. Essa conformidade leva à unicidade nos acontecimentos abordados, no entanto, há diferenças quanto ao tratamento e à visibilidade conferidos às matérias, o que é perceptível nos tempos atribuídos aos ângulos privilegiados, aos enquadramentos e à captação das imagens. Nessa perspectiva, e tendo em conta o caso em análise, fazem a abertura do prime-time, em todos os canais, as notícias referentes à visita do presidente Luiz Inácio Lula da Silva, em junho de 2003, e as da assinatura do acordo que permitiu a legalização dos imigrantes brasileiros em Portugal. São, também, notícias de abertura do prime-time a publicação pela revista Time da matéria sobre as redes de prostituição no Norte do país; a violência inusitada da morte de dois cidadãos de países do Leste Europeu na Baixa do Porto ou, ainda, a construção, por imigrantes recém-chegados, de um bairro clandestino nos arredores de Lisboa. Quanto à Agenda Política da Imigração, o tema mais focado é a legalização extraordinária dos imigrantes brasileiros em situação irregular e as alterações à Lei sobre Imigração.

No entanto, é preciso salientar que o cotidiano da agenda midiática atribui claramente valor notícia às matérias associadas ao crime, ao trabalho - na ótica dos acidentes ou exploração dos imigrantes pelos patrões, que nunca são identificados ou investigados pelos jornalistas -, e só por último à integração. Todas elas obedecem a critérios substantivos, nomeadamente ao grau e nível hierárquico dos indivíduos envolvidos no acontecimento noticiável e, sobretudo, à capacidade de o acontecimento suscitar interesse humano. Em uma apreciação geral, pode-se afirmar que o valor notícia atribuído aos conteúdos é o interesse humano, a personalização e a dramatização - elementos constitutivos da história leve e do infotainment-, que são constantes das matérias e dos canais, com espe-

11. HARTLEY, J. Los usos de la televisión (As funções da televisão). Barcelona: Paidós, 1999. p. 127-153; TV Globo. Jornal Nacional: a notícia faz história. Rio de Janeiro: Zahar, s/d. cial incidência nos operadores privados, mesmo quando se abordam temas de caráter político, econômico ou social. Existe, também, uma acentuada tendência em explorar a Agenda, atribuindo a uma questão e seus desdobramentos uma seqüência de várias matérias. Por exemplo, blocos de 10 a 25 minutos sobre as casas de Alterne (Prostituição) em Portugal. 
Imigrantes nos media portugueses • Isabel Maria Ribeiro Ferin da Cunha

É evidente que estas reflexões não apagam a exibição de programas, documentários e reportagens que envolvem boas práticas ou conceitos de responsabilidade social, como o são, por exemplo, o documentário A Leste do Paraíso, exibido pela SIC, ou o programa Nós, em que os imigrantes contam suas trajetórias de imigração, produzido pelo ACIME.

\section{ESTUDOS EXTENSIVOS SOBRE A COBERTURA JORNALÍSTICA DA IMIGRAÇÃO E DAS MINORIAS ÉTNICAS}

O primeiro estudo extensivo realizado em Portugal sobre esta temática refere-se a dados recolhidos em $2000^{12}$, num projeto elaborado com o patrocínio da Comunidade Européia e integrado num projeto internacional denominado Observatory Against Ethnic and Sexual Discrimination. Esse estudo, baseado em dados recolhidos ao longo de um ano, incidiu sobre a imprensa e a televisão. Constituíram o corpus de análise de imprensa quatro jornais diários (Público, Diário de Notícias, A Capital, 24 Horas) e dois semanários (Expresso e Independente). O corpus de televisão foi constituído por três jornais do prime-time emitidos na RTP1, RTP2 e SIC. A execução do projeto apoiou-se metodologicamente em diretivas emitidas pela Itália, o país coordenador do projeto, que dirigiu e administrou a construção de uma base de dados comum relativa aos países participantes. Os resultados apurados, em Portugal, tanto na televisão como na imprensa, apontam para uma grande visibilidade dos temas relacionados com discriminação étnica, assinalando-se 2.613 matérias na imprensa e 673 na televisão.

Entre $1^{\circ}$ de janeiro de 2001 e 31 de março de 2002, Rui Cádima e Alexandra Figueiredo desenvolveram um estudo sobre a imprensa, apoiado pelo Observatório da Imigração/ACIME, que incidiu sobre 4 mil matérias recolhidas na imprensa de âmbito nacional e regional ${ }^{13}$. A metodologia seguida envolveu técnicas quantitativas de análise de conteúdo, tendo em conta descritores temáticos e a tematização da informação sobre imigração, os imigrantes e as minorias étnicas. Os resultados apurados registram 2.782 inserções em publicações de âmbito nacional e 1.294 na imprensa regional, conferindo aos imigrantes oriundos do Leste maior protagonismo. Convém ainda salientar que este estudo aponta os delitos como sendo a temática mais tratada e identifica os temas racismo e xenofobia mais associados aos imigrantes africanos, imigrantes (em geral) e ciganos ${ }^{14}$.

Nos estudos seguintes realizados sobre dados recolhidos nos anos de 2003 e $2004^{15}$, o corpus de análise compreendeu a imprensa e a televisão. Não sendo possível tratar o universo de informação produzida na imprensa, avaliaram-se os jornais diários de âmbito nacional - Público, Diário de Notícias, Jornal de Notícias, Correio da Manhã, A Capital e o 24 Horas - e os semanários Expresso e Independente. Com a mesma ressalva, o corpus de televisão foi constituído por
12. FERIN, I. (Coord.). Media e discriminação: um estudo exploratório do caso português. Observatório, n. 5, p. 27-38, maio 2002.

13. CÁDIMA, R.; FIGUEIREDO, A. Representações (imagens) dos imigrantes e das minorias étnicas nos Media. Lisboa: Ol/ ACIME, 2003.

14. Ibid., p. 49-50.

15. FERIN, l. et. al. Media, imigração e minorias étnicas. Lisboa: OI/ACIME, 2004; FERIN, I.; SANTOS, C. A. Media, imigração e minorias étnicas II. Lisboa: OI/ACIME, 2006. 
comunicação \& educação • Ano XII • Número 2 • maio/ago 2007

matérias sobre imigração e minorias étnicas, veiculadas nos jornais televisivos do prime-time, nos canais RTP1, RTP2, SIC e TVI.

\section{EVOLUÇÃO NO TRATAMENTO DAS MATÉRIAS NA IMPRENSA E NA TV}

Vamos em seguida comparar os dados recolhidos em 2003 e 2004, relativos à imprensa e à televisão. Na imprensa, a comparação dos dois anos mostra que o número de matérias nos oito jornais que constituíram o corpus aumentou de 1.538 em 2003 para 1.791 em 2004, representando um acréscimo de 16,4\%. Quanto ao espaço ocupado pelas matérias analisadas, verificamos que houve, em 2004, um aumento daquelas que preenchem $1 / 4$ de página, o que corresponde a 29,2\% nos jornais de referência. Nos jornais de enfoque mais popular, a tendência de 2003 manteve-se, com as matérias com um ou dois parágrafos atingindo $39,5 \%$ delas.

As matérias relativas à imigração e às minorias étnicas surgem sobretudo na seção Sociedade, tanto nos jornais de referência como nos populares, correspondendo o gênero notícia a $51,5 \%$ (contra $44,4 \%$ em 2003). Deve-se registrar, porém, as exceções referentes aos dois semanários analisados (Expresso e o Independente), que apresentam um valor mais significativo da modalidade reportagem do que os restantes. Já nos jornais populares, a breve é o gênero com maior número de ocorrências no 24 Horas.

A situação jurídica em que se encontram os imigrantes é referida em 39,1\% das matérias em 2004, o que consubstancia uma grande diferença relativamente às referências a este aspecto em 2003, presentes em 46,9\% dos casos. A situação mais recorrente em 2004 na imprensa, à semelhança do que aconteceu em 2003, é a dos imigrantes sem documentos ou ilegais, em 67,3\% dos casos. Quanto à nacionalidade ou etnia a que pertencem os protagonistas das matérias, verificamos que em grande parte da amostra existe a tendência de agrupar várias minorias, registrando-se este fenômeno em 21,2\%. Curiosamente, os jornais mais populares dão maior realce a nacionalidades ou a etnias específicas - em 2004, são os brasileiros a atrair mais atenção (em 20,4\% dos casos), enquanto em 2003 ocuparam este espaço os cidadãos de países do Leste (em 22,2\% das matérias).

O tema mais freqüente na amostra recolhida em 2004 continua a ser o crime, em 13,4\% das matérias. O mesmo aconteceu em 2003, embora a incidência deste tema tivesse diminuído, já que no ano anterior o crime havia surgido em $17,9 \%$ delas. No entanto, nos jornais de referência não é este o tema mais freqüente: em 2004 foi o da integração (12,2\% das matérias) e, em 2003, o do trabalho $(15,7 \%)$.

Os atores mais freqüentes em 2004 continuam a ser os institucionais, com o SEF (Serviço de Estrangeiros e Fronteiras) à frente, embora de forma menos expressiva do que no ano anterior. Em 2003, o SEF surge em 20,5\% do total 
Imigrantes nos media portugueses - Isabel Maria Ribeiro Ferin da Cunha

de temas, enquanto em 2004 aparece em 15,8\%. O Governo emerge, em 2004, como o principal ator em quatro dos cinco jornais de referência analisados.

A presença masculina em 2004 corresponde a 47,7\% das notícias (contra 37,9 em 2003), sendo que, em 2003, os jornais de referência destacavam a presença feminina em $39,2 \%$ dos casos, em função da tematização prostituição. É de ressalvar ainda os dados relativos ao enquadramento - policial, o segundo mais freqüente, com uma ligeira queda em 2004 na ordem dos 5\% - e à personalização, em que se destacam os resultados obtidos pela modalidade Governo, com $12,2 \%$ do total de matérias.

No que concerne aos dados recolhidos e registrados nos jornais televisivos nos canais RTP1, SIC e TVI, constata-se que há mais matérias no total dos canais em 2004, sendo a SIC a estação que mais atenção concedeu a estes temas, contrariamente ao que aconteceu em 2003, ano em que a TVI exibiu mais notícias. No entanto, há que ter em conta que os dados referentes a 2003 cobriram nove meses, e não um ano como em 2004. Comparando, nos dois anos, os tempos de exibição das matérias, constatamos que há, também, diferenças, pois, se no primeiro ano de análise a maioria delas se situava entre os 1'45" e os 2'45", no segundo ano a maioria é inferior a 1'45".

No que se refere ao alinhamento, aos gêneros televisivos e cenários, os resultados são muito semelhantes nos dois anos, dado que as matérias sobre as temáticas imigração e minorias poucas vezes fazem a abertura dos jornais televisivos e normalmente são tratadas através de uma reportagem que tem as ruas e os locais de reunião como cenários habituais. No entanto, convém ainda referir que há um número significativo de registros (cerca de $10 \%$ nos dois anos analisados) que têm como cenários os locais de prostituição.

No ano de 2004, a nacionalidade brasileira $(18,5 \%)$ continua a ser a mais representada, tal como aconteceu em 2003 (26\% dos registros), mas com valores mais próximos da ucraniana (14\%), a segunda comunidade mais retratada individualmente no ano de 2004. Note-se, contudo, que, tanto em 2003 como em 2004, o número de matérias que se reportam a várias comunidades, isto é, a imigrantes de várias origens, é bastante semelhante, atingindo $20 \%$ do total.

Assinala-se, ainda, que os registros referentes à comunidade cigana, em 2004, são percentualmente inferiores a 2003 e, apesar de se ter autonomizado, no último ano, o indicador Segundas gerações, isto é, referências a filhos e netos de imigrantes afro-descendentes, não adquirem valores significativos.

Salientam-se, em especial, as alterações referentes à situação jurídica dos imigrantes, verificada em 2004, tendo em conta que em 2003, ou não foi possível identificar a situação jurídica dos imigrantes ou, quando foi possível, os mais representados eram majoritariamente indocumentados (43\%). Na verdade, constata-se que em 2004 a maioria das matérias refere-se a titulares de autorização de permanência (mais de $40 \%$ delas), seguindo-se aquelas que focam os indocumentados e os ilegais $(32 \%)$.

Nos dados referentes aos temas, o crime obtém sensivelmente o mesmo valor percentual nos dois anos $(15,5 \%)$. Um valor que adquire outra dimensão 
comunicação \& educação • Ano XII • Número 2 • maio/ago 2007

(35,4\% do total dos temas registrados) quando agregado a outras temáticas, tais como violência, máfias, exploração e prostituição. No entanto, verifica-se, no ano de 2004, um crescimento acentuado dos temas ligados às questões sociológicas da imigração, incluindo-se as referências às políticas inclusivas. Essa tendência faz-se igualmente sentir nos discursos sobre o crime -, o que está patente nos resultados registrados nas variáveis do discurso -, em que os imigrantes e as minorias tendem a surgir como vítimas e não como agressores.

Os atores mais referidos nesses dois anos analisados são os Imigrantes, que adquirem quase $50 \%$ das menções registradas no total das matérias. É de notar que, em 2004, os atores identificados, os Populares, os Especialistas e os Empresários, captam valores significativos, sendo que as Forças de Segurança, ao contrário do que se verificou em 2003, alcançam um valor percentual muito inferior ao ano anterior (em 2003, cerca de 50\% do total dos atores e, em 2004, apenas $19,5 \%)$.

Os discursos produzidos na televisão sobre tais temáticas mostram uma clara mudança entre 2003 e 2004, sendo possível aventar que se mantêm as mesmas imagens, mas inscritas em outros textos. Assim, por exemplo, enquanto em 2003 o tipo de narrativa dominante na matéria era policial (36,2\%), em 2004 era o factual (40,8\%), seguido do policial (35,1\%). O Tom Negativo apresenta resultados muito semelhantes em $2003(59,4 \%)$ e 2004 (52,4\%). A estes resultados deve-se acrescentar um ligeiro aumento de matérias com Tom Neutro, que evoluíram de 23,7\%, em 2003, para 25,7\% em 2004. Nos dois anos analisados registra-se que as vozes mais citadas são as dos Populares, as dos Especialistas, seguindo-se as vozes dos Cidadãos dos países do Leste e dos Brasileiros. Ao contrário de 2003, o Governo e as Forças de Segurança têm menor expressão.

É de referir ainda um estudo não publicado, uma dissertação de mestrado, que parte precisamente dos resultados obtidos pela análise do corpus do trabalho publicado pelo ACIME, incidindo na imagem das mulheres imigrantes ${ }^{16}$ veiculada pela imprensa. Este estudo, intitulado "Imagens da mulher imigrante na imprensa portuguesa: análise do ano 2003", reduz o universo de análise para 210 das 1.538 notícias recolhidas nesse ano, já que foram selecionadas as que dizem respeito exclusivamente a mulheres imigrantes ou pertencentes a um grupo considerado minoritário na sociedade portuguesa. O tema lato da imigração feminina é objeto de um tratamento jornalístico preferencialmente sucinto (ocupando até 1/4 de página, em notícias ou breves, raramente em reportagens ou entrevistas), enquadrado nas seções de Sociedade ou Nacional

16. Algumas das conclusões deste trabalho encontram-se publicadas em artigo no livro de SANTOS, C. A. Mulheres imigrantes na imprensa portuguesa. Resenha da análise do ano de 2003 In: VV.AA. Imigração e etnicidade: vivências e trajectórias de mulheres em Portugal. Lisboa: SOS Racismo, s/d. (ou equivalentes). Apesar de muitas matérias surgirem com âmbito geográfico nacional $(24,6 \%)$, verificamos que mais de $40 \%$ situam-se no Norte ou interior de Portugal, o que representa uma distorção da imagem das mulheres imigrantes relativamente aos dados estatísticos existentes. Esse fenômeno está associado à tematização dominante - a prostituição ou Alterne (59\% dos casos) - e também à nacionalidade e ao estatuto jurídico predominantemente atribuído pelas notícias às mulheres imigrantes: brasileiras (em 44,1\% dos casos em que é referida etnia ou nacionalidade) e ilegais (em quase $50 \%$ delas). 
Imigrantes nos media portugueses - Isabel Maria Ribeiro Ferin da Cunha

Em conclusão, na imprensa portuguesa as mulheres imigrantes, pelo fato de serem consideradas minorias das minorias, não vêem reforçada ou retratada a sua verdadeira essência, aquela que se traduz no desempenho cada vez mais relevante, de funções produtoras e reprodutoras, biológicas e culturais, nas sociedades de acolhimento, exceto naquelas em que se verifica o tratamento da imigração feminina enquanto problemática, e não como acontecimentos.

\section{CONCLUSÃO}

A apresentação destes dados mostra que a imprensa e a televisão têm tido um papel importante na construção das imagens sobre a imigração e as minorias étnicas. Nesse percurso, convém frisar o papel que o rádio tem realizado na sensibilização dos portugueses - mais próximos historicamente da emigração que da imigração - a esse fenômeno. Salienta-se, ainda, que a televisão é, na sociedade portuguesa, a primeira fonte de informação, o que lhe confere funções de serviço público e de responsabilidade social.

Por outro lado, é notório que o tratamento de tais temáticas se encontra vinculado a fatores sociais, como a situação política e econômica, ao mercado dos media e às pressões inerentes às instituições diretamente implicadas na gestão e acolhimento dos imigrantes. Nessa perspectiva, não é possível identificar um padrão de cobertura destas temáticas, mas sim padrões em evolução. Por outro lado, é também necessário frisar que a pesquisa sobre os media é uma tarefa simultaneamente complexa e ambígua, pois, ao mesmo tempo que se propõe analisar o produto informação, utiliza-o como dados de conhecimento.

Resumindo, ao longo destes anos, e sobretudo a partir de 2001, têm crescido as boas práticas na imprensa de referência, identificáveis em função dos seguintes indicadores: pertinência da linguagem, vocabulário e tom utilizado; nomeação dos atores sociais, sua origem e situação jurídica; nomeação de fontes, pluralidade de fontes, utilização de dados estatísticos; qualidade e pertinência da informação veiculada, contextos da informação, diversificação das temáticas na óptica dos interesses dos imigrantes e da sociedade de acolhimento; preocupação quanto ao serviço ao público com a disposição gráfica e quanto à construção de leads, colunas e caixas; critérios na seleção de fotografia e na utilização de elementos de infografia.

No que se refere ao meio televisão, sobretudo no prime-time, há ainda muito a fazer. No entanto, podemos adiantar que o ano de 2004 trouxe algumas alterações que apontam para uma maior responsabilidade no tratamento das matérias, nomeadamente na voz e tempos atribuídos aos imigrantes e comunidades nas reportagens realizadas. Essa tendência também é perceptível no recurso a dispositivos tecnológicos menos estigmatizantes para as comunidades, bem como na utilização de fontes alternativas e na busca de temas que possam interessar às comunidades visadas e à sociedade em geral. 
Resumo: Neste artigo, faz-se um balanço das imagens e representações nos media da imigração e das minorias étnicas em Portugal, com ênfase no início do milênio. Levam-se em consideração os fatores da globalização e o contexto europeu, e evidencia-se o papel da imprensa, mas sobretudo da televisão portuguesa, na criação de estereótipos sobre as comunidades imigrantes. Para concluir, refere-se que a cobertura desta temática tem estado sob análise de entidades reguladoras portuguesas e européias, nomeadamente pela implementação de estudos científicos e ações de formação para jornalistas.

Palavras-chave: análise, media, migrações, minorias, Portugal, estudos quantitativos.
Abstract: In this article, we have a balance of the images and representations of immigrants and ethnic minorities in Portuguese media. It considers the factors of globalization and European context, highlighting the role of press, and mainly Portuguese television, in the creation of communities of immigrant's stereotypes. It is mentioned, in the conclusion that this subject coverage has been under analysis by Portuguese and European regulator entities, mainly by implementing scientific studies and formation actions for journalists.

Keywords: analysis, media, migrations, minorities, Portugal, quantitative studies. 